\title{
O aumento da produção científica odontológica brasileira na saúde pública
}

O aumento da produção científica odontológica brasileira, de uma forma geral, pode ser verificado pelo crescimento do número de artigos publicados em periódicos odontológicos por pesquisadores afiliados a universidades brasileiras, no MEDLINE, que é o maior acervo internacional de revistas científicas sobre saúde: até $1980=2 ; 1981$-1985 = 0; 1986 $1990=16 ; 1991-1995=216 ; 1996-2000=461 ; 2001-2005=1.564$.

Especificamente na saúde pública, esse aumento pode ser ilustrado pelo crescimento do número de artigos no Community Dentistry and Oral Epidemiology, Community Dental Health e Journal of Public Health Dentistry: até $1980=0 ; 1981-1985=0 ; 1986-1990=0 ; 1991$ 1995 = 5; 1996-2000 = 7; 2001-2005 = 17. Cadernos de Saúde Pública e Revista de Saúde Públi ca também têm registrado um aumento marcante no número de artigos odontológicos: CSP publicou 1 artigo no período 1991/1995, 9 no período 1996/2000 e 52 entre 2001/2005; RSP publicou 7 artigos no período 1991/1995, 19 entre 1996/2000 e 25 entre 2001/2005.

Uma forma de avaliar a qualidade de um artigo é verificar quanto interesse o mesmo despertou nos pesquisadores da área. Se o artigo despertou interesse, ele passou a fazer parte dos antecedentes de novos estudos sobre o tema e foi utilizado como argumento em discussões de achados subseqüentes, sendo citado em artigos posteriores.

Quantidade de artigos não pode ser interpretada como, necessariamente, qualidade da produção científica. Ter artigos publicados é condição necessária, porém não suficiente, para o desenvolvimento científico. É importante que os pesquisadores, revisores e editores encarem a difícil tarefa de contribuir com o desenvolvimento científico e não meramente publicar um número cada vez maior de artigos, se os mesmos têm poucas chances para tal. Por exemplo, estudos sobre a prevalência da cárie dentária em uma determinada localidade têm poucas chances de contribuir para o desenvolvimento científico. Apesar disso, vários artigos publicados pela odontologia brasileira na saúde pública, nos últimos anos, foram relatos desse tipo ou similares.

É importante que junto com esse salto positivo na quantidade haja uma busca pela qualidade. Para que isso ocorra, é necessário que pesquisadores identifiquem problemas relevantes com base em alguma teoria sólida e interessante, formulem hipóteses específicas e que os dados sejam coletados e analisados para testá-las.

Uma outra tendência negativa é a reprodução de estudos já suficientemente repetidos em outras populações. A menos que haja uma boa justificativa de por que algo que aconteceu repetidamente em outras populações não irá acontecer na população brasileira, a replicação de estudo similar no Brasil tem poucas chances de contribuir com o desenvolvimento científico.

Concluindo, o aumento do número de artigos em periódicos científicos, de uma forma geral, sinaliza um desenvolvimento positivo em direção a uma postura mais científica e o aumento específico do número de artigos voltados para a saúde pública ilustram o interesse crescente da odontologia brasileira na saúde da população. Para contribuir com o desenvolvimento científico e com a saúde da população, a odontologia brasileira deve preocuparse não somente com a quantidade, mas também com a qualidade dos artigos publicados.

Paulo Nadanovsky

Instituto de Medicina Social, Universidade do Estado do Rio de Janeiro, Rio de Janeiro, Brasil. nadanovsky@ims.uerj.br 